\title{
Preliminary archaeological survey and remote-sensing of shell mounds at Kwokkunum, Albatross Bay, Cape York Peninsula, Australia
}

\author{
Joshua Emmitta, ${ }^{\mathrm{a}}$, Kasey Allely ${ }^{\mathrm{a}}$, Benjamin Davies ${ }^{\mathrm{b}}$, Eloise Hoffman ${ }^{\mathrm{c}}$ and Simon J. \\ Holdaway ${ }^{\mathrm{a}, \mathrm{d}}$ \\ ${ }^{a}$ School of Social Sciences, The University of Auckland, Private Bag 92019, Auckland 1142, New Zealand; \\ ${ }^{b}$ Department of Anthropology, 260 S Central Campus Drive, University of Utah, Salt Lake City, UT 84112-0060, \\ USA; ${ }^{\mathrm{c}}$ Rio Tinto, Communities and Future Workforce - Weipa Aluminium, 123 Albert Street, Brisbane, QLD 4000,

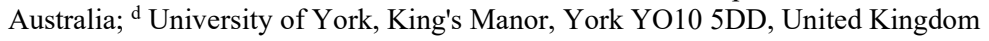 \\ * Corresponding author josh.emmitt@auckland.ac.nz
}

\begin{abstract}
Shell mounds are a prominent part of the Cape York Peninsula archaeological record. A short period of fieldwork allowed initial assessment of their presence, size, and shape in the Kwokkunum region, Albatross Bay. Shell mounds found in this area vary in size with some examples amongst the largest found in the Cape York Peninsula. Comparison of terrestrial and airborne LiDAR data suggests that shell mounds in areas like Kwokkunum may be identified remotely where mound slopes exceed 5$10^{\circ}$. However, vegetation provides significant challenges for shell mound recording and vegetation on the mounds impacts on their form and preservation. Some of the challenges the largest mounds pose for investigation are reviewed.
\end{abstract}

\section{Introduction}

Despite decades of research in the Albatross Bay region, we are only beginning to understand the chronology of mound formation, variation in the size and shape of mounds, and the processes that led to the form of the mounds that we see today. A preliminary survey undertaken in 2017 in the Kwokkunum region of Albatross Bay, Queensland, Australia identified the extent of the archaeological features including shell mounds in an area close to recently developed bauxite mining operations. Kwokkunum is notable for a number of large shell mounds up to $10 \mathrm{~m}$ in height. The size of these mounds, among the largest in the Albatross Bay region, provide particular challenges for research and significance assessment. We describe the survey work in Kwokkunum and assess the use of airborne light detection and ranging (LiDAR) data to remotely identify and measure the dimensions of mound features. Results are compared with terrestrial LiDAR data to discuss the challenges and benefits of both methods. Using the results from the survey, we consider the challenges for assessing archaeological and Aboriginal cultural significance presented by the Kwokkunum archaeological record.

\section{Background}

Mounds primarily composed of Tegillarca granosa (Linnaeus 1758), (syn. Anadara granosa) shells are a common feature of the shorelines of estuarine rivers discharging into Albatross Bay. Shell mound numbers are estimated at over 500 (Bailey et al. 1994) but most remain under-studied (Bailey 1977; Morrison 2010; Shiner et al. 2013, and given the lack of systematic survey in many parts of the region the true number may be considerably higher. Mounds occur at several locations along the banks of the four major rivers, the Pine, Mission, Embley, and Hey (Bailey 1975; Morrison 2010; Stone 1992). From surface observations, the bivalve $T$. granosa appears to be the dominant shellfish species for over $80 \%$ of known mounds (Morrison 2010:165). Although over $50 \%$ of known shell deposits are located within $250 \mathrm{~m}$ of the coastline (Morrison 2010:162), shell deposits are found on many different landforms such as coastal plains, relict sand ridges, mangrove mud (i.e. within the mangrove forest), and on the bauxite plateau (Bailey et al. 1994:78-79; Morrison 2010:166, 2013).

Similar shell deposits occur throughout coastal areas of northern Australia (e.g. Bourke 2004; Cochrane 2014; Faulkner 2009; Harrison 2009; Rosendahl et al. 2014). Like the Albatross Bay examples, these are noteworthy for their range of shapes and sizes, from dispersed scatters to large heaps of shell exceeding $13 \mathrm{~m}$ in height, and for their uniformity in composition (Bailey et al. 1994; Morrison 2010, 2013). Estimates of shell mound size were previously made using measurements and mathematical equations (e.g. Bailey 1994), however, precise measurements of surface area and volume were largely lacking until the recent availability of LiDAR and photogrammetry technologies (Larsen et al. 2017); therefore much research remains to document the form and extent of these archaeological features.

Kwokkunum is the name given to the area running along the southern banks of the Embley River, loosely bounded by the Hey River to the west and Aurukun to the south (Figure 1). Kwokkunum refers to a traditional canoe landing and camping site on the coast of the area (Kreij 2016:7). Mangrove forest and mudflats line the riverbanks that form part of the area, extending inland along major stream channels, and saltpans fringe these areas in some places. A low-lying basin occurs in the north central section of the area, flanked by sclerophyll forest on the inland slopes that descends from the bauxite plateau to the south. Frequent natural and anthropogenic fires contribute to a patchy coverage of ground vegetation seen today.

Initial studies by Stanner (1961) and Bailey (1977) identified the presence of shell mounds at Kwokkunum. At the time these first studies were undertaken, the primary research questions concerned whether the shell mounds were anthropogenic or natural features, a question that most scholars now believe has been resolved in favour of the 


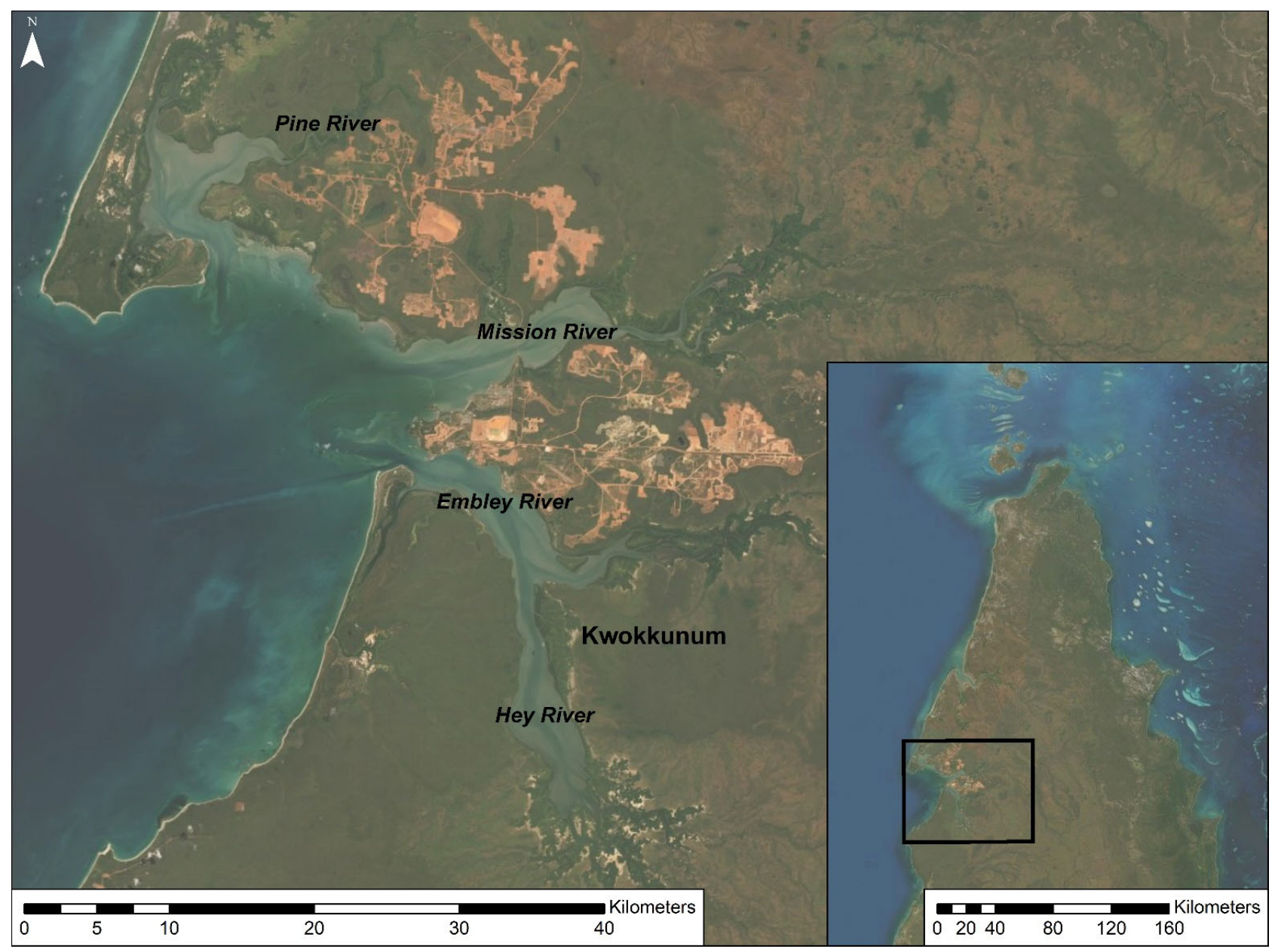

Figure 1. The Kwokkunum area with bordering rivers and location in Cape York

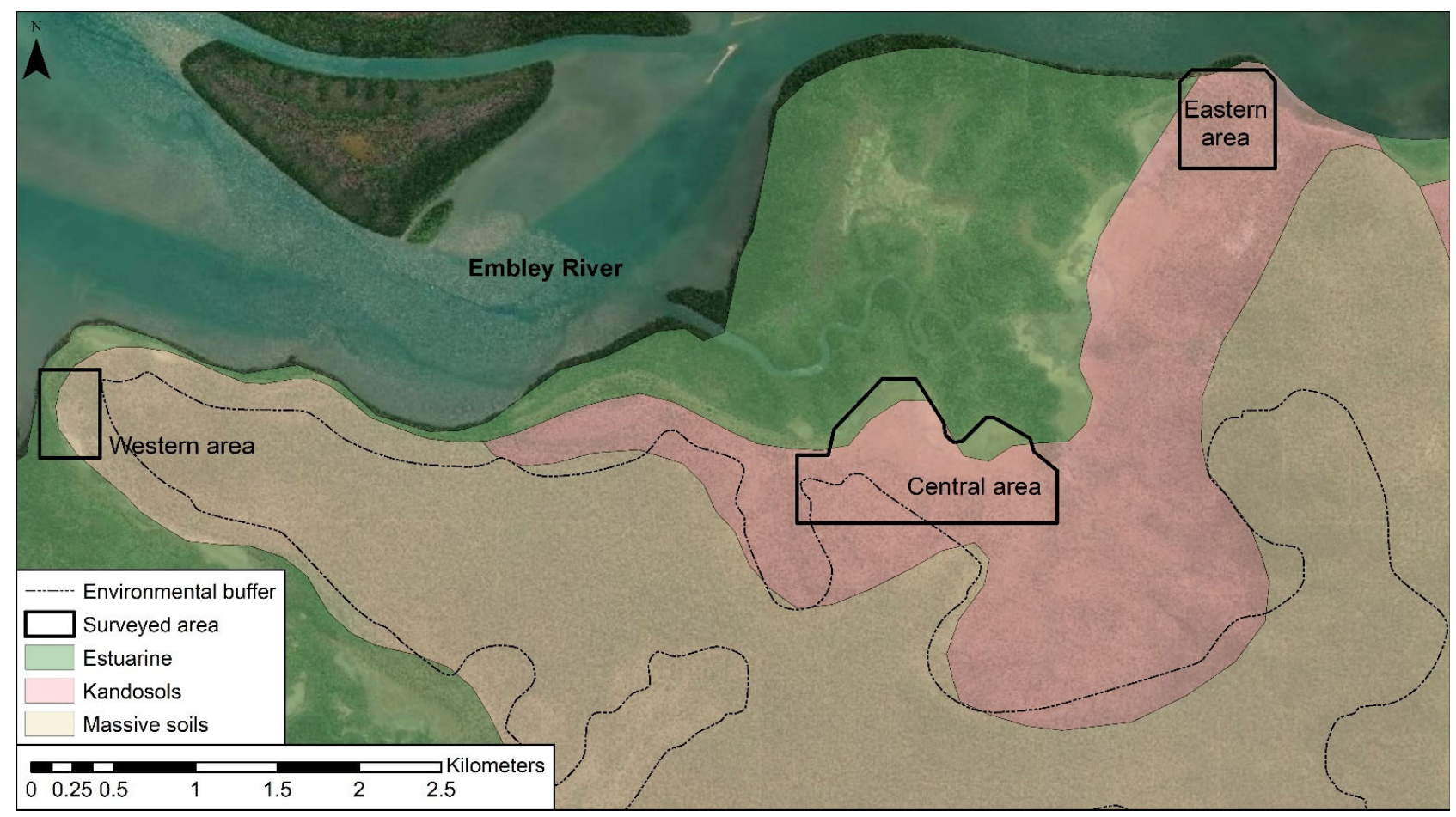

Figure 2. Geological landforms within the Kwokkunum survey area, showing the environmental buffer, two main survey areas (Eastern and Central areas), and the Western area discussed in the text. 
former (Hiscock 2007). Photographs and maps of shell mounds attributed to Kwokkunum were produced by these studies, but no further intensive investigations occurred, and exact locations and detailed descriptions of the mounds originally located are lacking. Subsequent to these studies but prior to 2011 when work connected with Rio Tinto mining leases began, archaeological investigation specific to the Kwokkunum area were limited to site recording of two shell mounds alongside a creek feeding into the Hey River on the western part of the area (Morrison 2002). A fishing hut was present on top of one of these mounds (SE-SM1) and the shape of the mound was reportedly altered 'probably with the use of the bobcat that sits on the western face of the site' (Morrison 2002:3). Morrison (2002) described SE-SM1 as a mounded shell deposit approximately $2 \mathrm{~m}$ in height from the substrate, and approximately $8 \mathrm{~m}$ in diameter. The second mound, SE-SM2 was a low-lying shell deposit, no more than $30 \mathrm{~cm}$ in height. Both deposits were predominantly composed of $T$. granosa (estimated at greater than $95 \%$ in proportion). The smaller deposit was notable for the frequency of ironstone clasts located on the surface (Morrison 2002).

Beginning in 2011, in preparation for the South of Embley (SoE) Bauxite Project (now Amrun Operations), six cultural heritage surveys undertaken by Rio Tinto investigated the portion of mining lease ML7024 south of the Embley River. Taken together, these surveys documented 525 scarred trees, 23 surface stone artefact scatters (totalling 43 artefacts), and 111 shell mounds or shell scatters (Rio Tinto Alcan Pty Ltd 2011:11-13). Heritage monitoring work and informal trips to the SoE Project area resulted in the location and recording of additional cultural heritage places. Places of cultural heritage significance within the SoE Project area are concentrated in coastal areas and are not equally or evenly distributed across space (Rio Tinto Alcan Pty Ltd 2011:11-3). Consequently, a large number of archaeological sites are located outside of the Project infrastructure footprint or in environmental buffer zones. Sites that do occur within the SoE Project area are predominantly scarred trees and, to a lesser extent, stone artefact scatters.

Although shell mounds have been noted at Kwokkunum in earlier surveys, accurate locational information and detailed descriptions are lacking for most. The 2017 survey aimed to identify shell mounds and archaeological features within the Kwokkunum environmental buffer, undertake survey of the boundaries of shell mounds to generate a baseline understanding of site variability, and demonstrate the feasibility of 3D model-building using remotely-sensed data for assessing shell mound sites. In this paper, we discuss the outcomes of the survey work and discuss methodological issues concerning the use of terrestrial and aerial light detection and ranging (LiDAR) for assessing shell mounds.

\section{Kwokkunum Local Environment}

The surveyed area is located across three landforms (Figure 2). The first, closest to the Embley River, is composed of recent deltaic estuarine sediments of silt, clay, and minor sand (Estuarine). The second, located further inland, is composed of poorly sorted clayey quartoze sandstone and granule conglomerate, pebbly in places, and interbedded sandy claystone (Kandosols). The third landform, and the most inland, is often referred to locally as the bauxite plateau and can be summarised as aluminous laterite, including bauxite and 'ironstone' below it (Massive Soils) (Smart 1977).
The Eastern survey area (discussed below) was largely off lease and therefore outside the project impact zone being completely contained within the environmental buffer. It encompasses two main vegetation units (Rio Tinto Alcan Pty Ltd 2011) (Figure 3). The dominant vegetation unit consists of estuarine wetlands made up of mangrove species such as Rhizophora stylosa (red mangrove) and Bruguiera gymnorhiza (large-fruited orange mangrove) with Avicennia marina (grey mangrove) sometimes occurring along the outer edges of the mangrove forest. The ground is bare of herbaceous plants, however, the prop roots of Rhizophora spp. form a dense arching framework above the mud. In some areas, Ceriops tagal (yellow mangrove) forms stands and comprises both the canopy species and understorey with occasionally interspersed $A$. marina. Although archaeological survey of the mangrove forest is challenging, the Wathayn survey on the northern banks of the Embley River identified two shell mounds (WP-SM122 and WP-SM123) within the mangrove forest (Holdaway et al. 2017).

The second vegetation unit occurs on erosional plains and rises, and is dominated by eucalypts, particularly Eucalyptus tetrodonta (Darwin stringybark) (Rio Tinto Alcan Pty Ltd 2011). Other eucalypt species can contribute to the canopy, including Corymbia clarksoniana (Clarkson's bloodwood) and Corymbia disjuncta (cabbage gum) or Eucalyptus leptophleba (Molloy red box). Erythrophleum chlorostachys (Cooktown ironwood) is present and can sometimes codominate the canopy. Sub-canopy species occurring in this vegetation unit include Melaleuca viridiflora (broad-leaved teatree), Grevillea glauca (bushman's clothes peg), Grevillea parallela (silver oak), and Parinari nonda (nonda). The sparse shrub layer includes younger eucalypt species and also features Xylomelum scottianum (woody pear), Planchonia careya, and Pogonolobus reticulatus (medicine bush). Grasses dominate the ground layer, including Heteropogon triticeus (giant spear grass), Sarga plumosum (plume sorghum), Eulalia mackinlayi (brown silky top), Eriachne sp. (wanderrie grass) and Schizachyrium spp. (fire grass). At the edge of the bauxite plateau, Eucalyptus cullenii (Cullen's ironbark) either dominates or is codominant with $E$. tetrodonta. The sparse understorey features different species such as Planchonia careya (cocky apple). The shrub layer may also vary in species composition from those in the dominant vegetation unit featuring Croton arnhemicus (hard cascarilla), and Decaschistia peninsularis. The vegetation on the erosional plains and rises obscures the surface in many areas and forms dense vegetation caps on the tops of the majority of the shell mounds. This poses challenges for archaeological survey and recording discussed further below. In addition to the vegetation, bioturbation through invertebrate activity (primarily termites) refreshes the surface, and in places additional surface disturbance occurs through the action of ungulates (pigs and cattle). This limits the ability to identify stone artefact scatters and, in some cases, lowdensity shell deposits.

The Central survey area is the larger of the two study areas, extending out of the environmental buffer to the south. The surveyed area sits almost entirely within the second vegetation unit described above and extends downslope onto the saltpan. However, at the time of survey, burning had removed much of the surface vegetation, leaving the ground bare of grasses and shrubs. The saltpan directly behind the mangrove forest was bare and exposed apart from plant taxa 


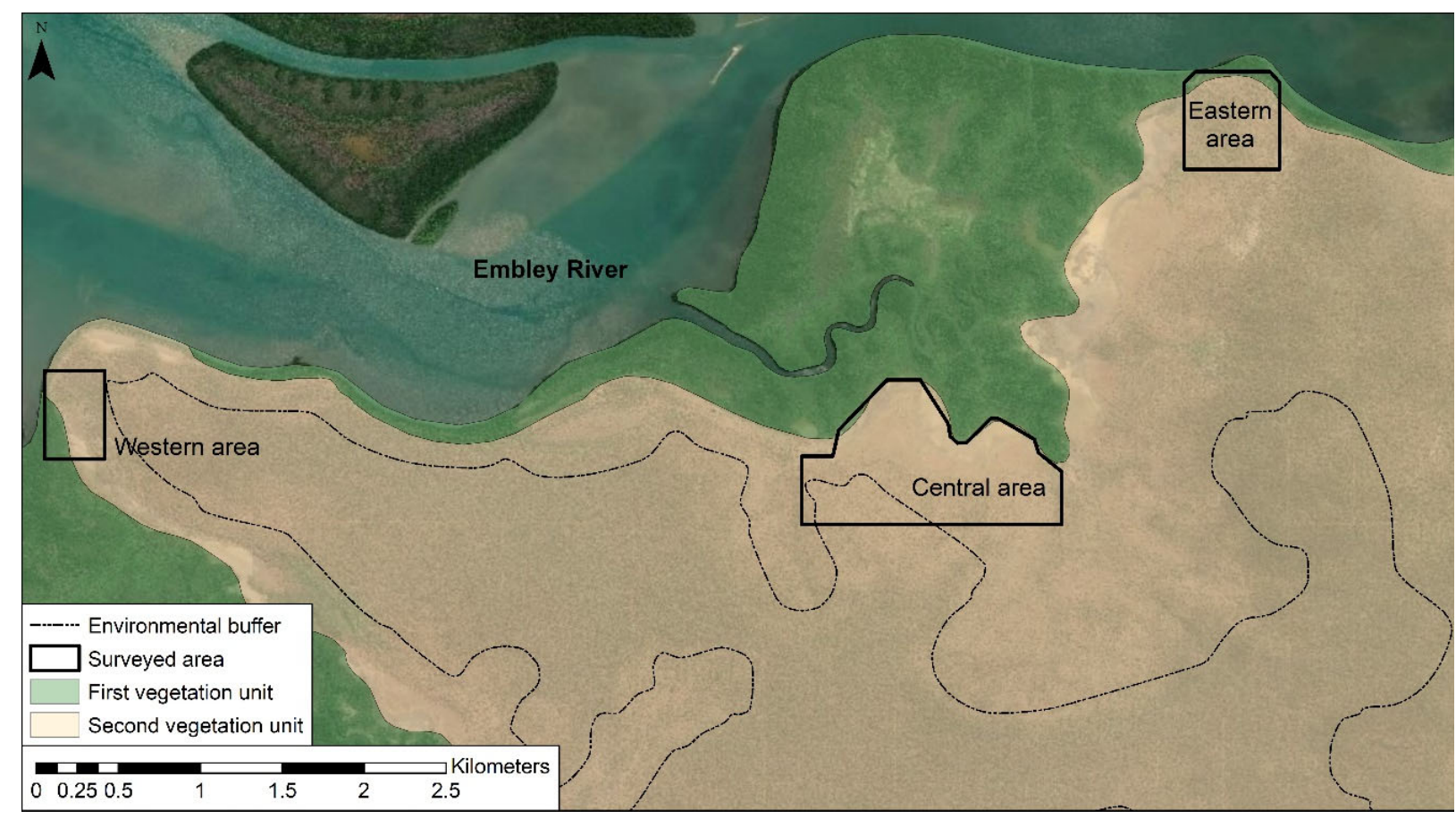

Figure 3. The two main vegetation units at Kwokkunum, with the environmental buffer, two main survey areas (Eastern and Central areas), and the Western area described in the text.

growing on top of the shell mounds. Consequently, the mounds featured very large and established trees different to the surrounding area. Cribb's $(1986,1996)$ investigation of shell mounds in the Aurukun region to the south of Albatross Bay proposed several reasons for the prevalence of differing species on top of the largest mounds: their preference for calcine soil matrix, absence of competition, and protection from burning due to their location on the bare floodplain. Away from the shell mounds and the salt flats, leaf litter and high grasses obscured surface visibility in places where burning had not recently occurred. Trees frequently obscured direct views of the mounds, posing issues for terrestrial LiDAR scanning, that we discuss in more detail below.

\section{Survey Methods}

Previous studies describe the shell mounds of the western Cape York Peninsula as occurring in a range of sizes and shapes and situated in different vegetation zones and geomorphic settings (e.g. Bailey et al. 1994; Morrison 2013). At Kwokkunum, some shell mounds are very large, in some cases larger than $10 \mathrm{~m}$ in height. At these heights, the Kwokkunum mounds are among the largest in Albatross Bay and indeed among the largest structures by volume created by Aboriginal people before European contact. However, as in other areas, Kwokkunum has mounds of a range of sizes including low-density shell scatters that only rise a short distance above the surface. Obtaining precise measurements of shell mound dimensions has proved challenging for archaeologists for reasons that we outline below.

\section{Airborne LiDAR}

Preliminary assessment of Kwokkunum shell mounds made use of elevation data at a resolution of $1 \mathrm{~m}$ generated for Rio Tinto using airborne LiDAR recorded between 11-15
September 2010 , at an altitude of $1400 \mathrm{~m}$, with a minimum point density of 2 points $/ \mathrm{m}^{2}$, and a spatial accuracy to within $0.2 \mathrm{~m}$. Conversion of the LiDAR-generated ground points into a triangular irregular network allowed examination of mound anomalies using hill-shading in ESRI ArcMap. Airborne LiDAR data permits visualisation of landsurfaces beneath vegetation allowing the identification of potential shell mounds. While airborne LiDAR allows identification of large mounds (those greater than $1 \mathrm{~m}^{3}$ in relief), it is not currently suitable for detecting smaller mounds and shell scatters, due to shallow surface topographies. Distinguishing larger mounds from background surface undulations may be difficult and errors in LiDAR data may at times produce spurious results. Therefore, airborne LiDAR data provides a guide for ground surveys aimed at verifying the nature of the mounds identified. In our study, a visual examination of the airborne LiDAR data was undertaken prior to surveys to aid in feature identification and this helped direct the groundtruthing activities over the course of the survey period.

\section{Pedestrian Survey}

Initial ground-truthing surveys followed a dogleg route from the Eastern to the Central area, then along the coastal flats to the banks of the Hey River. Recording of shell mound feature locations used a handheld GPS. A subsample of areas with mounds were subject to a more intensive pedestrian survey (i.e. the Eastern, Central, and Western areas) (Figure 2). At a minimum, this involved recording GPS locations and taking photographs of shell mounds identified. Where time permitted, records included the perimeters of shell mounds, and detailed descriptions of shell mound condition and matrix surface composition.

A Trimble GeoExplorer 6000 GPS provided shell mound perimeter measurements. The visible extent of the shell mound was recorded when the slope from the mound met the 


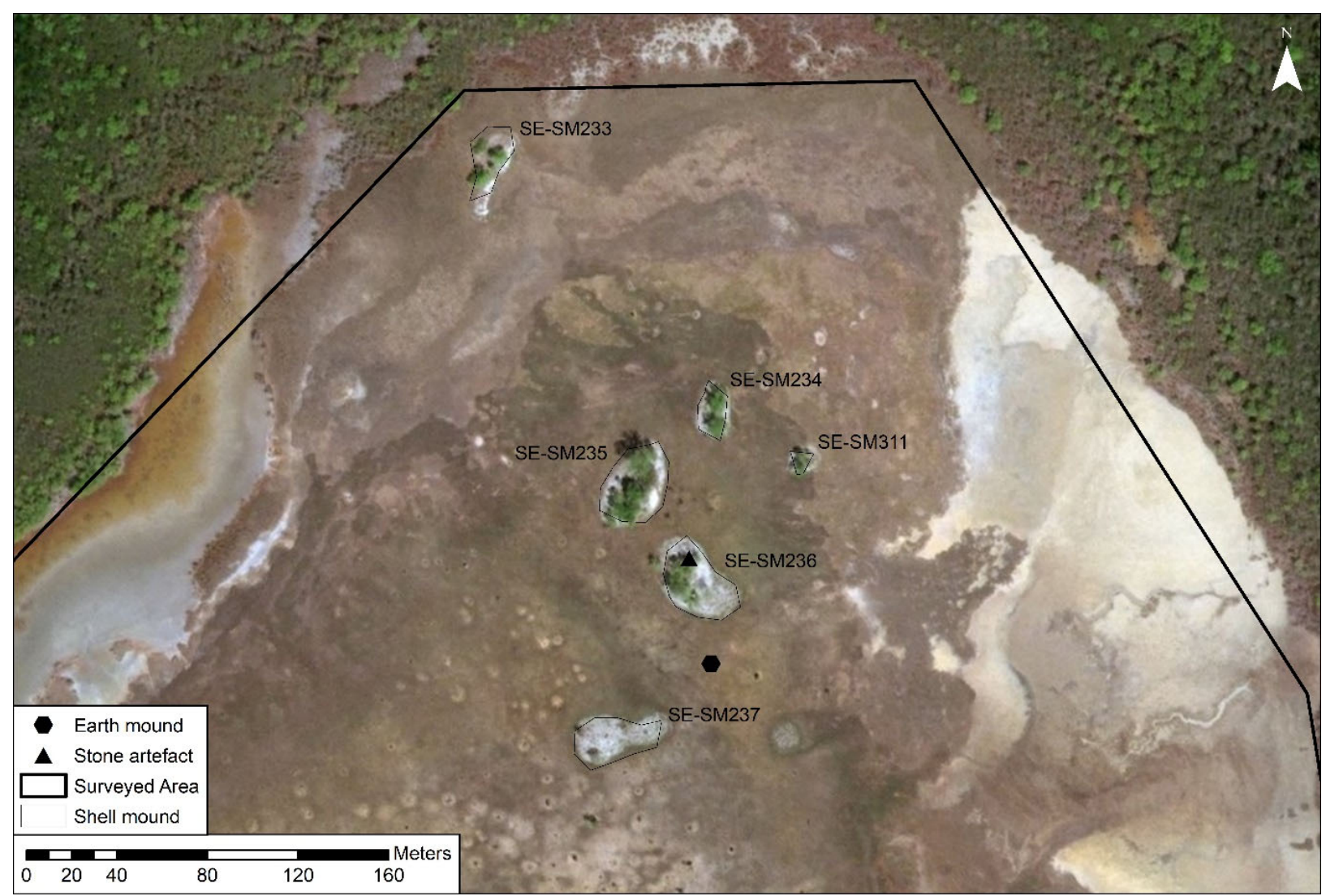

Figure 4. The Central area with the scanned mounds.

surrounding topography and/or no more shell was visible on the surface. Shell mounds are composed of moveable sediment clasts (e.g. shells), so determining the edges of shell mounds is not always straightforward. In many cases, lowdensity shell scatters surround the perimeters of mounds. These form ragged 'edges' that may become buried, making it difficult to determine from the surface where one mound begins and another ends. The boundaries recorded therefore reflect the surveyors' best estimate of where the primary concentration of shell ends, and the mound edge might begin. In some cases, surface vegetation litter that obscured shell scatters required clearance.

\section{Terrestrial LiDAR}

Six shell mounds in the northern extent of the Central area were selected for terrestrial LiDAR scanning in order to determine the feasibility of using this technique at Kwokkunum and to determine mound size and shape following the methods discussed by Larsen et al. (2017). Data obtained from these mounds also permitted comparison with dimensions obtained from airborne LiDAR (see below). This group of mounds was located on a flat coastal plain, recently fired, thereby reducing but not eliminating obstruction from vegetation as discussed below (Figure 4). Fifty-five scans were taken using a Faro Focus3D X 330. Of these, 13 scans used the $>20 \mathrm{~m}$ outdoor setting to provide landscape coverage in large areas between and around the mounds while the remaining 42 scans used the $<20$ m outdoor setting in closer proximity to the mounds.
Terrestrial LiDAR scans focused around four mounds in the Central region (SE-SM311, SE-SM234, SE-SM235, SESM236) with additional scans around mounds SE-SM233 and SE-SM237. Processing of the scan data used Faro SCENE 2019.1 software. Automatic registration (i.e. the stitching together) of multiple scans was made difficult by the large area covered, grasses that obscured mound edges, trees that obscured mound tops, and the uniformity of the shell matrix which provided few landmarks. To mitigate these issues, registration was undertaken manually, which increased the time required to process the scans. In future, the use of scanner targets (spheres) would provide useful visualisation of the common points needed for registration.

The points for each mound were isolated and separately exported to a computer-aided design (CAD) program, Blender $\mathrm{v} 2.8$. Deletion of points representing vegetation left the points representing mounds. The cleaned point cloud was subject to mesh construction via Delaunay triangulation, a method used in computational geometry. For a given set of discrete points, triangles formed between sets of three points in such a way that no point is located inside the circumcircle of any triangle. Smoothing of the mesh formed by lines connecting point triangles further reduced the effect of any outlying points that represented vegetation as opposed to the ground surface. Surface area calculation used the sum of the surface areas of the component triangles. Calculating volume required creation of a flat base formed by projecting a plane between the lowest mesh extents across the mound perimeter to create a closed mound volume, with volume calculation based on this shape. 


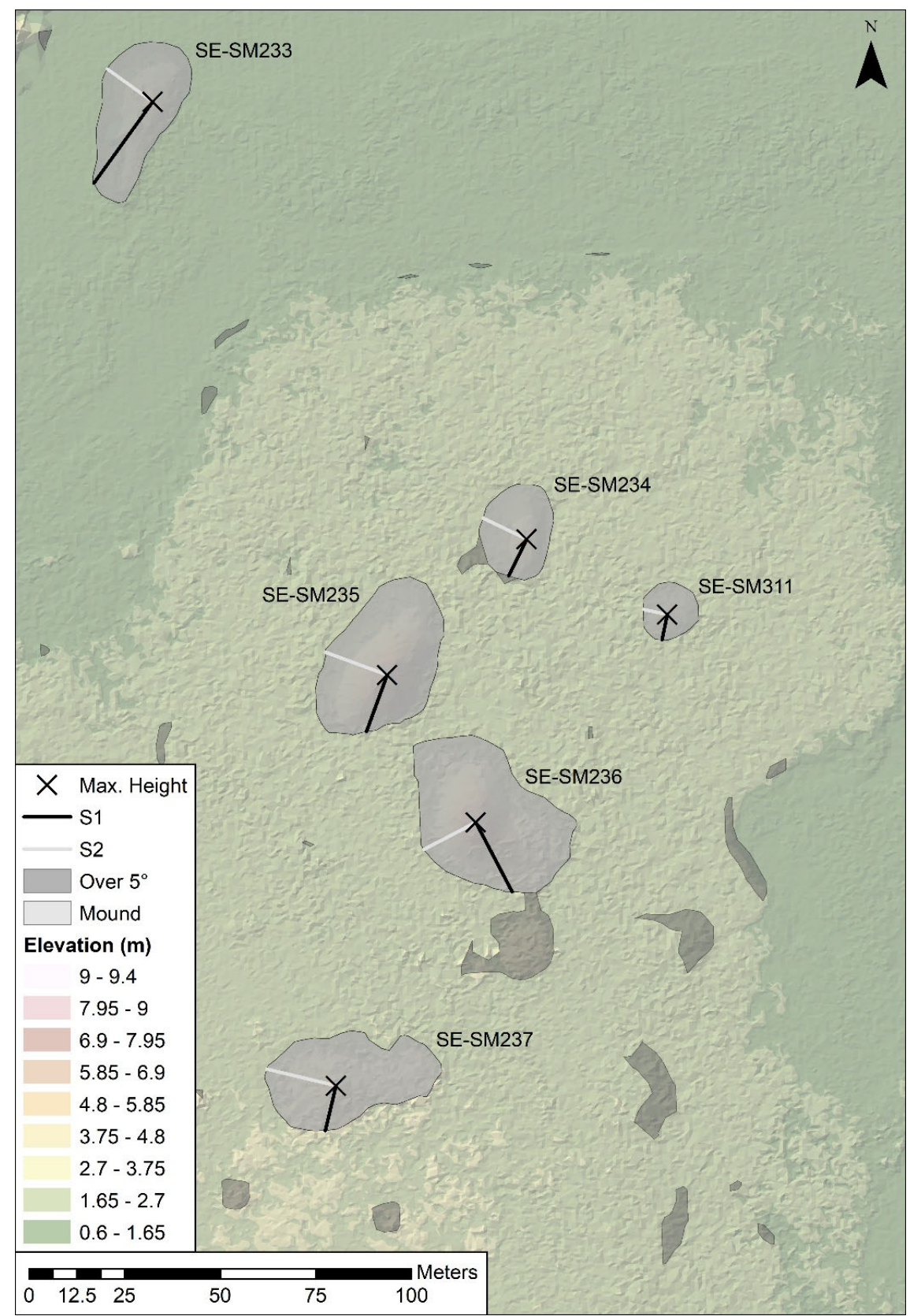

Figure 5. Mounds calculated from airborne LiDAR data, with their highest point marked by a cross. The lines S1 and S2 allow calculation of slope angles.

\section{Assessing Shell Mound Morphology from Remotely- Sensed Data}

Shell mound characteristics can be estimated geometrically using remotely-sensed and locally obtained data. Given the relatively high resolution of data available in the form of both terrestrial and airborne LiDAR for the survey area, it was possible to test the feasibility of calculating the required shell mound measurements using airborne data, as attempted elsewhere (Davis et al. 2019).

Mound identification using airborne LiDAR points involved the use of a slope calculation. Points were exported from airborne LiDAR data and used to calculate slopes using the geographic information system, ESRI ArcGIS. Sets of points that formed a perimeter with a slope in excess of an arbitrary value of $5^{\circ}$ indicated the presence of a potential mound (Figure 5). While the slope value is arbitrary, it provided the minimum value below which surface undulations markedly increased the number of potential mounds identified.

Once identified, mound height calculations were obtained using the difference between the highest points observed in LiDAR data within mound perimeters obtained during surveys compared to the ground surface immediately outside the perimeter. Heights obtained in this way are necessarily approximations since the basal topography of the mounds is unknown. Thus, if the ground rises beneath a shell mound, the apparent height of the mound will not reflect the true depth of the shell deposits. This measure provides a rough estimate, but one that can be uniformly applied. 


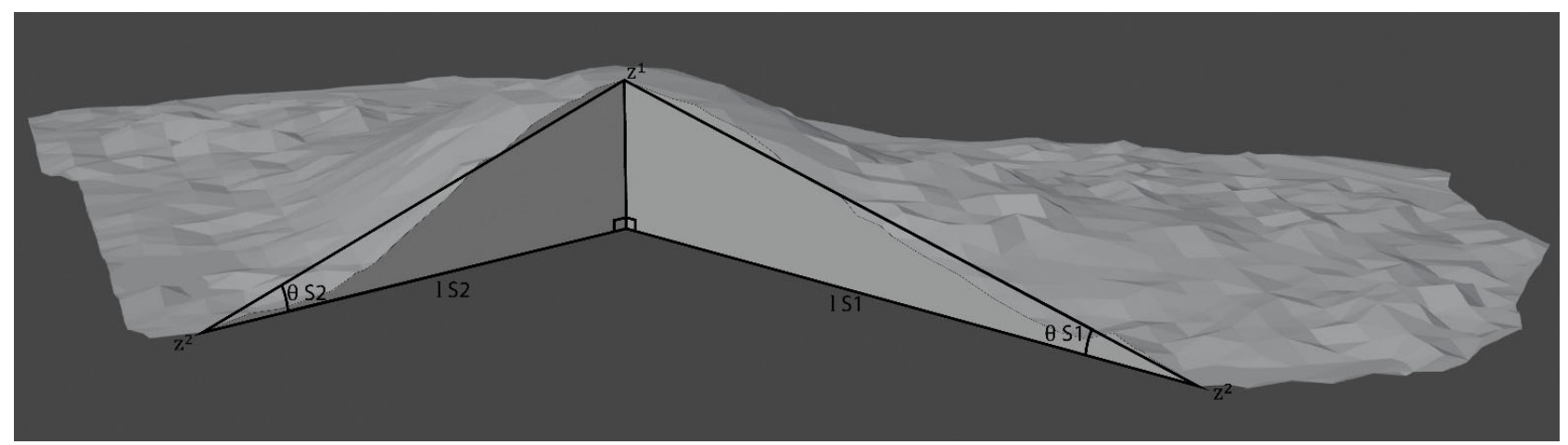

Figure 6. Cross-section of shell-mound SE-SM236, showing triangles used to construct slope angles based on points identified from airborne LiDAR data (grey surface).

Next, the geometric aspect calculation involved deriving slope measurements for the major and minor axes. Using a point representing the highest elevation of the mound (calculated relative to points immediately outside the slope derived perimeter) and extending a line from this point to the perimeter of the mound along the average aspect value for the mound (S1 line) allowed calculation of the S1 angle. A second line extended in the same way but orthogonal in a clockwise direction (the minor axis, S2 line), allowed calculation of the S2 angle (Figure 6). In each case, these lines formed part of a right-angled triangle with the right angle at the base and centre of the mound and the angle $\theta$ adjacent to the perimeter (Figure 6). Relative to this triangle, calculation of the length of the adjacent $(l)$ S1 line and S2 line came from the GIS measurement of the linear, horizontal distance from mound centre to the periphery. Calculation of the length of the opposite used the height of the perimeter subtracted from the height of the highest point of the mound. Calculation of the angle $\theta$ used the formula:

$$
\theta=\arctan \frac{z^{1}-z^{2}}{l}
$$

Here $z^{1}$ is the height of the mound, $z^{2}$ is the height of the point where the line intersects the perimeter, and $l$ is the length of the adjacent $\mathrm{S} 1$ line and $\mathrm{S} 2$ line. Solving for $\theta$ provides the $\mathrm{S} 1$ and S2 angles. These measurements provide a measure of two-dimensional shape (expressed as the aspect ratio), where the shape assumes the plan shape of the mound is approximately ellipsoidal. This calculation is also possible in the field without the use of terrestrial LiDAR, as heights to determine slope are available from a GPS unit.

Exporting the airborne LiDAR derived point cloud to Blender v2.8 CAD software enabled maximum length, width, height, surface area, and volume calculations. This software converts the point cloud into meshes described above, with separate meshes created for the mounds and the surrounding landscape between the mounds. Meshes used Delaunay triangulation with the area for each mound isolated from both the mound and landscape meshes. Surface area was calculated from the summed areas of the Delaunay triangles for each mound. Comparing the isolated landscape that surrounded mound perimeters and using this to estimate planes below the mounds, together with mound meshes, provided the means to calculate volume and the maximum dimensions (Figure 6).

\section{Results}

Visual inspection of the airborne LiDAR data identified 88 potential shell mounds in the area not covered by previous surveys (Figure 7). Most of these potential mounds occur close to the current edge of the mangrove forest, with some extending inland along creek lines. This is consistent with mound locations identified in previous surveys in other parts of the Albatross Bay area (e.g. Holdaway et al. 2017; Morrison 2010). A possible cluster of mounds further east from the survey area identified in LiDAR analysis were not field checked, nor was a single possible mound in the Western area occurring inside the mangrove vegetation unit.

Pedestrian surveys conducted in the Eastern and Central areas recorded the locations of 38 shell mounds (Figure 8). Of these, perimeters were obtained for 31 mounds, and detailed descriptions were obtained from 16 mounds. The survey area in the east of Kwokkunum measured approximately $0.34 \mathrm{~km}^{2}$, while the Central area covered $0.98 \mathrm{~km}^{2}$. In addition to shell mounds, eight culturally-modified trees (CMT) were recorded during the survey (Figure 8). CMT are also a common feature in northern Australian landscapes, and are associated with woodworking and food procurement from sugarbag bees (Shiner and Morrison 2009). Very few portable artefacts were identified during the survey. Stone flakes and cores made from quartz and quartzite occurred in very low numbers (less than $1 / \mathrm{m}^{2}$ ) at both the Eastern and Central study areas. None of the artefacts encountered was identifiable as a formal tool type, excepting a notable find of a fragment of a sandstone grinding dish with a maximum length of $14 \mathrm{~cm}$ at the base of SE-SM236 (Figure 9). Scarred trees and artefacts were photographed, and their GPS locations recorded.

Shell mounds were composed primarily of $T$. granosa, with Telescopium telescopium, Geloina expansa, Nerita balteata, Marcia hiantina, and Volegalea sp. also present in smaller numbers based on identifications from the surface of the shell mounds. The condition of surface shells varied substantially between mounds, with some composed primarily of whole and broken valves, while others were highly fragmentary and compacted. Soil formation and tree growth occurred at the tops of most mounds. Differences in composition are likely to have an impact on mound size and shape. 


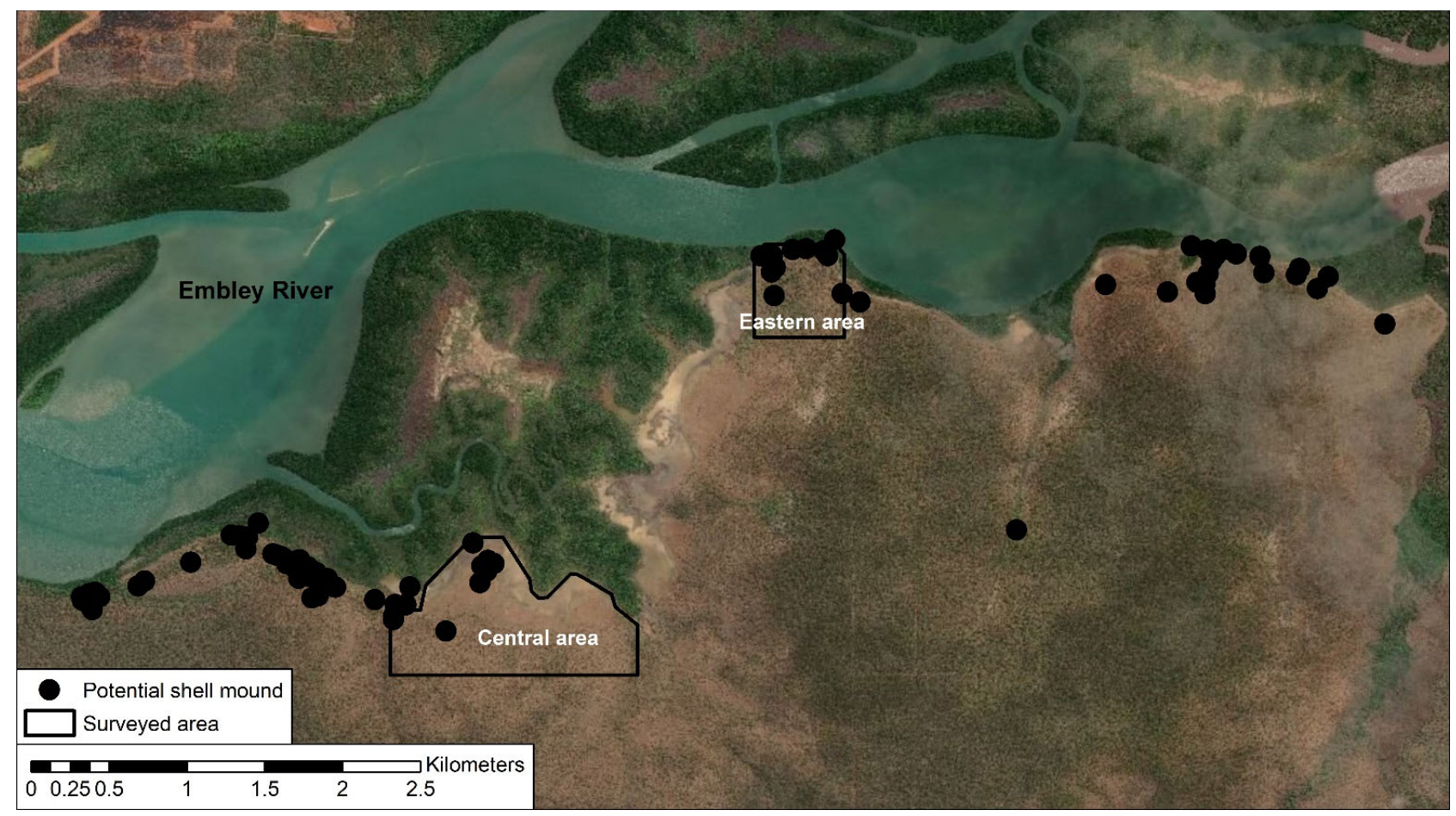

Figure 7. Potential shell mounds identified from airborne LiDAR data.

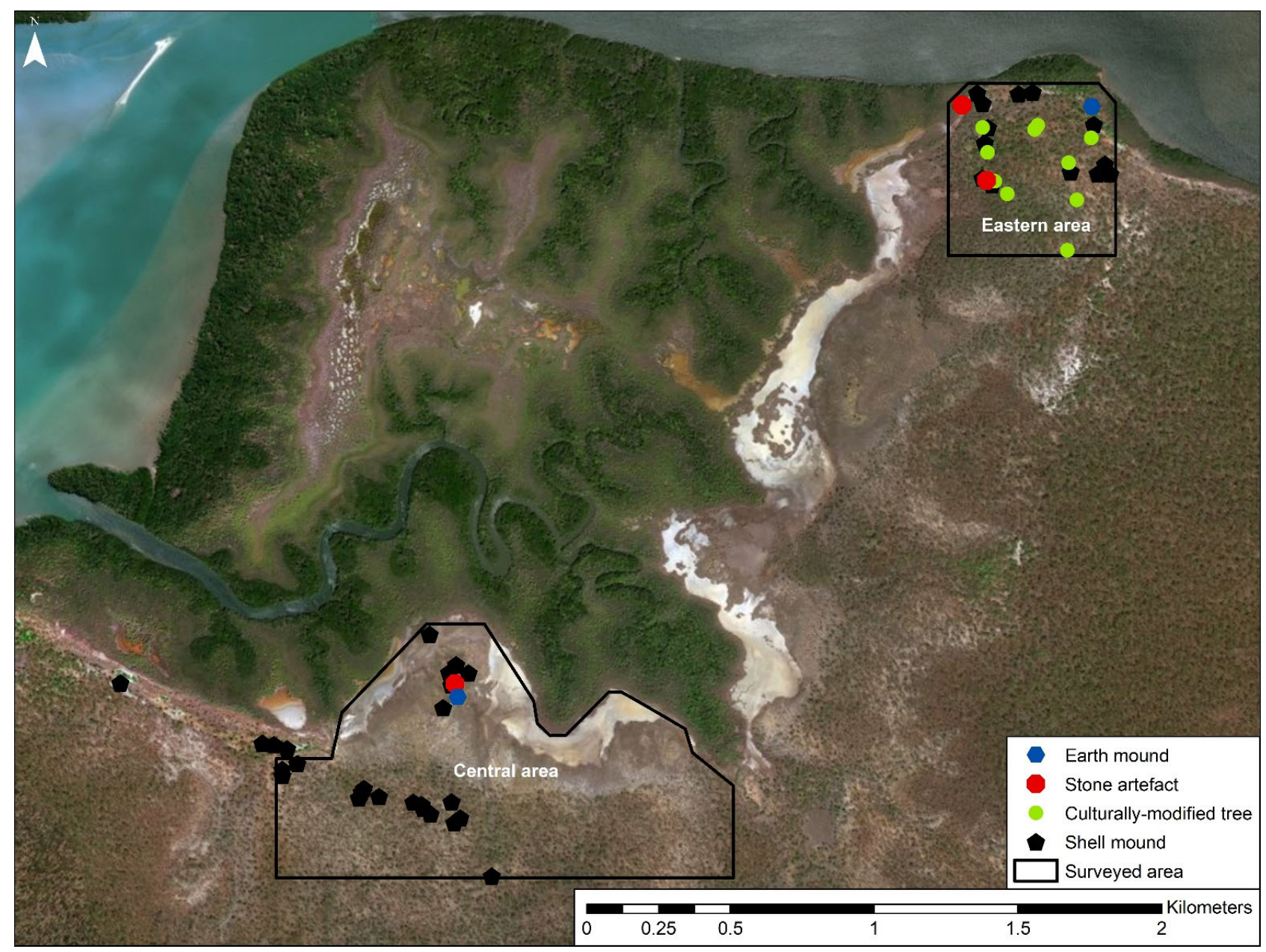

Figure 8. Surveyed areas as well as the locations of identified shell mounds, earth mounds, culturally-modified trees, and stone artefacts. 


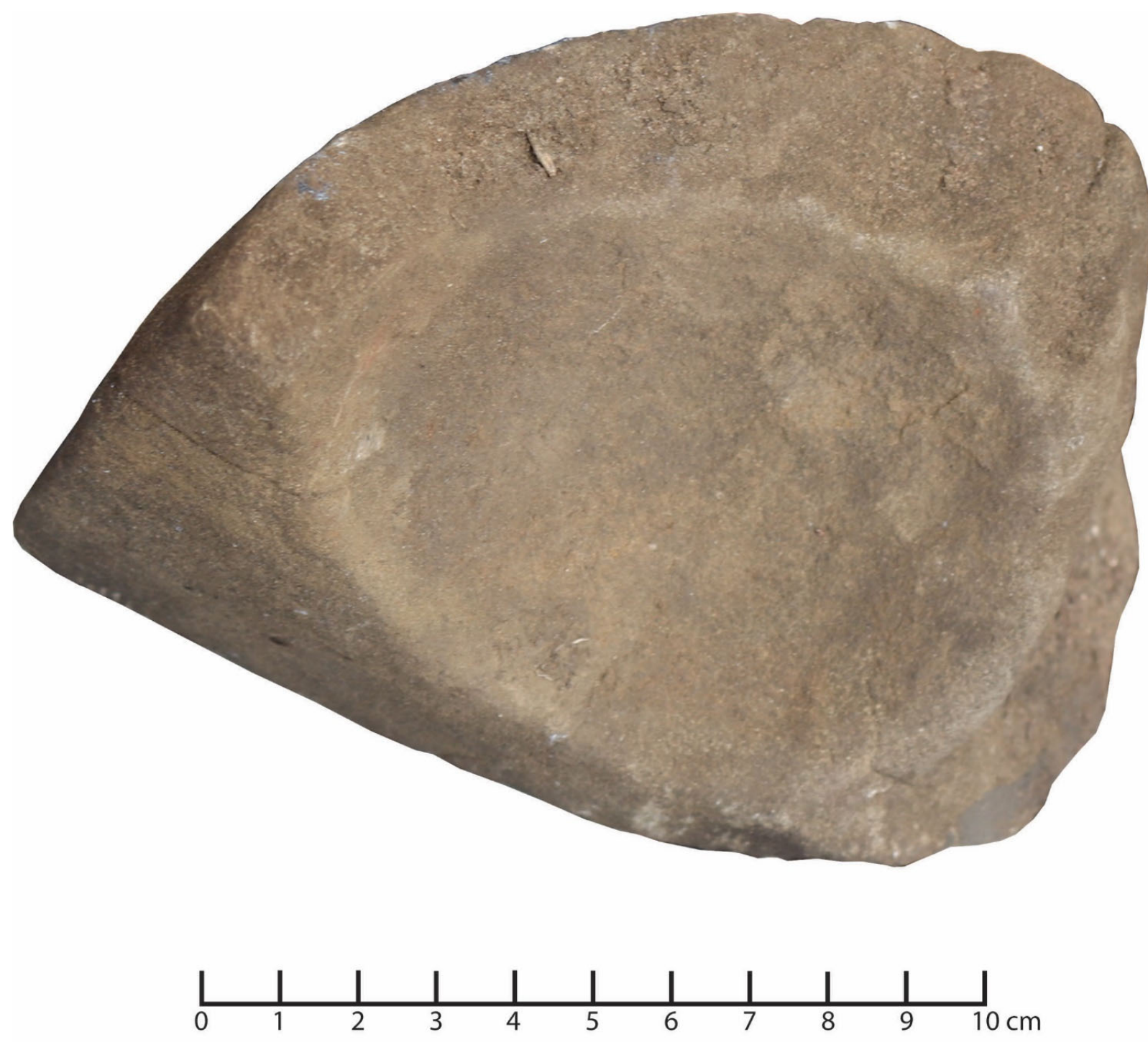

Figure 9. Sandstone grinding dish from the base of SE-SM236.

The accuracy of airborne LiDAR for the detection of shell deposits produced mixed outcomes when compared with the in-field survey. In the Central area, airborne LiDAR showed nine possible shell mounds, however survey detected 21 shell deposits of various sizes and one earth mound. In the Eastern area, 11 mounded features were visible using the airborne LiDAR derived terrain data. Survey in this area detected 13 shell deposits and one earth mound. This outcome is particularly interesting because some mounded features consisted of a number of mounded shapes that when surveyed on the ground, proved to be continuously joined by shell deposits. Mounds not identified by the LiDAR analysis were typically shell scatters and mounds smaller than $1 \mathrm{~m}$ in height and therefore with forms difficult to differentiate in the airborne LiDAR data from the natural topography.

\section{Characterising Mound Morphology using Terrestrial and Airborne LiDAR}

Despite burning of the Central area prior to the survey, vegetation was still an issue during the terrestrial LiDAR scanning process. In particular, shell mounds identified on the ridge to the south of the Central area were identified under tree cover, and while the lack of low vegetation aided in their identification, they were still difficult to identify from a distance, which is why pedestrian survey was required. In the Central area vegetation burning left tufts of grass, as well as trees on the mounds. The terrestrial LiDAR scans therefore required editing prior to volume calculations.

Mound height measurements varied across the study areas, with most mounds less than $2 \mathrm{~m}$ in height (Figure 10).

Taller mounds occur in the Western area, some possibly exceeding $10 \mathrm{~m}$ in height, but these were not visited during the survey period (see below). As noted above, while a flat base for the mounds may not represent the actual base shape, in the absence of more accurate data the approach used here provides a consistent approximation for mound volume estimation. The Blender software also allowed maximum length, width, and height calculation (Table 1). 


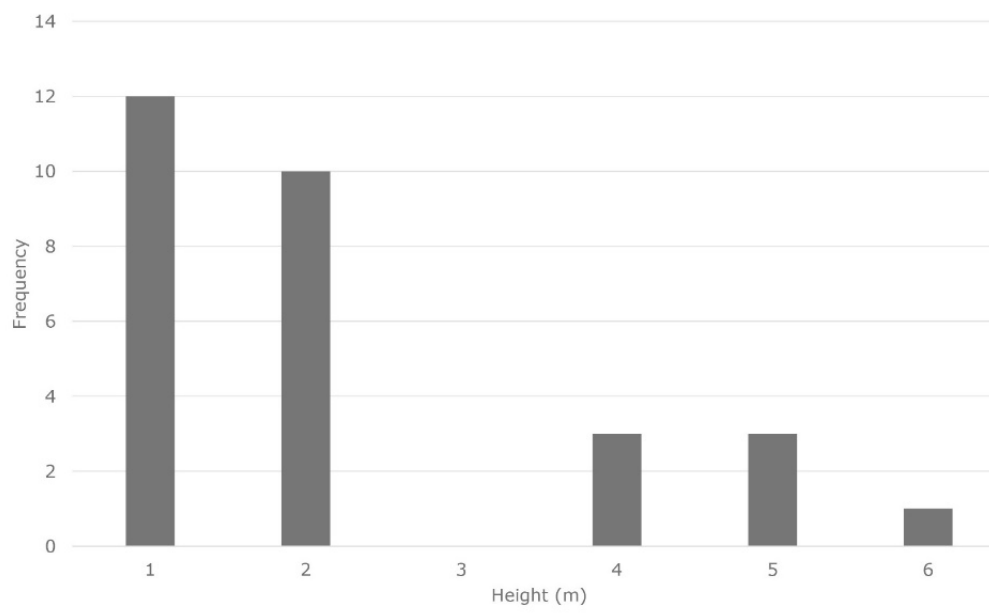

Figure 10. Shell mound height frequency within the field study areas.

Table 1. Dimensions, surface areas, and volumes of the shell mounds from the Central area calculated from terrestrial LiDAR.

\begin{tabular}{|c|r|r|r|r|r|}
\hline Mound & \multicolumn{1}{c|}{$\begin{array}{c}\text { Length } \\
(\mathbf{m})\end{array}$} & \multicolumn{1}{c|}{$\begin{array}{c}\text { Width } \\
(\mathbf{m})\end{array}$} & \multicolumn{1}{c|}{$\begin{array}{c}\text { Height } \\
(\mathbf{m})\end{array}$} & \multicolumn{1}{c|}{$\begin{array}{c}\text { Surface } \\
\text { Area } \mathbf{( m}^{\mathbf{2}} \mathbf{)}\end{array}$} & \multicolumn{1}{c|}{$\begin{array}{c}\text { Volume } \\
\left(\mathbf{m}^{\mathbf{3}}\right)\end{array}$} \\
\hline SE-SM233 & 39.1 & 21.0 & 1.79 & 783.60 & 223.56 \\
\hline SE-SM234 & 29.1 & 16.4 & 1.65 & 541.70 & 185.35 \\
\hline SE-SM235 & 42.8 & 34.5 & 4.91 & 1222.58 & 1072.81 \\
\hline SE-SM236 & 45.9 & 40.0 & 4.88 & 957.73 & 1094.62 \\
\hline SE-SM237 & 47.3 & 29.9 & 1.65 & 1434.13 & 360.04 \\
\hline SE-SM311 & 14.3 & 11.3 & 0.82 & 147.57 & 29.89 \\
\hline
\end{tabular}

Table 2. Dimensions, surface area, slope, and volume of the shell mounds from the Central area calculated from airborne LiDAR.

\begin{tabular}{|c|c|c|c|c|c|c|c|c|}
\hline Mound & $\begin{array}{c}\text { Length } \\
\text { (m) }\end{array}$ & $\begin{array}{c}\text { Width } \\
\text { (m) }\end{array}$ & $\begin{array}{c}\text { Height } \\
\text { (m) }\end{array}$ & $\begin{array}{c}\text { S1 O } \\
\left({ }^{\circ}\right)\end{array}$ & $\begin{array}{c}\text { S2 } \boldsymbol{\theta} \\
\left(^{\circ}\right)\end{array}$ & $\begin{array}{c}\text { Aspect } \\
\text { Ratio }\end{array}$ & $\begin{array}{c}\text { Surface } \\
\text { Area }\left(\mathbf{m}^{2}\right)\end{array}$ & $\begin{array}{c}\text { Volume } \\
\left(\mathbf{m}^{3}\right)\end{array}$ \\
\hline SE-SM233 & 42 & 25.8 & 1.83 & 3.65 & 6.88 & 0.53 & 681.81 & 279.14 \\
\hline SE-SM234 & 25 & 19.4 & 1.67 & 7.01 & 7.34 & 0.96 & 382.79 & 172.43 \\
\hline SE-SM235 & 41.3 & 33.5 & 4.77 & 14.98 & 14.51 & 1.03 & 1030.88 & 1098.19 \\
\hline SE-SM236 & 42.6 & 41.1 & 4.71 & 11.78 & 15.92 & 0.74 & 1279.03 & 1193.05 \\
\hline SE-SM237 & 46.2 & 26.1 & 1.89 & 7 & 4.97 & 1.41 & 852.27 & 295.54 \\
\hline SE-SM311 & 15.1 & 14.6 & 0.83 & 4.80 & 5.29 & 0.91 & 176.32 & 41.94 \\
\hline
\end{tabular}

Table 3. Dimensions, surface area, and volume of the shell mounds from the Central area calculated from the terrestrial and, in brackets, airborne LiDAR data.

\begin{tabular}{|l|l|l|l|l|l|}
\hline \multicolumn{1}{|c|}{ Mound } & \multicolumn{1}{|c|}{$\begin{array}{c}\text { Length } \\
(\mathbf{m})\end{array}$} & \multicolumn{1}{|c|}{$\begin{array}{c}\text { Width } \\
(\mathbf{m})\end{array}$} & $\begin{array}{c}\text { Height } \\
\mathbf{( m )}\end{array}$ & \multicolumn{1}{|c|}{$\begin{array}{c}\text { Surface Area } \\
\left(\mathbf{m}^{\mathbf{2}}\right.\end{array}$} & \multicolumn{1}{|c|}{$\begin{array}{c}\text { Volume } \\
\left(\mathbf{m}^{\mathbf{3}}\right)\end{array}$} \\
\hline SE-SM233 & $39.1(42)$ & $21(25.8)$ & $1.8(1.8)$ & $783.6(681.8)$ & $223.6(279.1)$ \\
\hline SE-SM234 & $29.1(25)$ & $16.4(19.4)$ & $1.7(1.7)$ & $541.7(382.8)$ & $185.4(172.4)$ \\
\hline SE-SM235 & $42.8(41.3)$ & $34.5(33.5)$ & $4.9(4.8)$ & $1222.6(1030.9)$ & $1072.8(1098.2)$ \\
\hline SE-SM236 & $45.9(42.6)$ & $40(41.1)$ & $4.9(4.7)$ & $957.7(1279)$ & $1094.6(1193.1)$ \\
\hline SE-SM237 & $47.3(46.2)$ & $29.9(26.1)$ & $1.7(1.9)$ & $1434.1(852.3)$ & $360(295.5)$ \\
\hline SE-SM311 & $14.3(15.1)$ & $11.3(14.6)$ & $0.8(0.8)$ & $147.6(176.3)$ & $29.9(41.9)$ \\
\hline
\end{tabular}


Table 4. Dimensions, surface area, slope, and volume of the potential shell mounds from the Western area calculated from airborne LiDAR.

\begin{tabular}{|c|c|c|c|c|c|c|c|c|}
\hline Mound & $\begin{array}{c}\text { Length } \\
\text { (m) }\end{array}$ & $\begin{array}{c}\text { Width } \\
\text { (m) }\end{array}$ & $\begin{array}{c}\text { Height } \\
\text { (m) }\end{array}$ & $\begin{array}{c}\text { S1 O } \\
\left({ }^{\circ}\right)\end{array}$ & $\begin{array}{c}\text { S2 } \theta \\
\left(^{\circ}\right)\end{array}$ & $\begin{array}{c}\text { Aspect } \\
\text { Ratio }\end{array}$ & $\begin{array}{c}\text { Surface } \\
\text { Area }\left(\mathbf{m}^{2}\right)\end{array}$ & $\begin{array}{c}\text { Volume } \\
\left(\mathbf{m}^{3}\right)\end{array}$ \\
\hline 1 & 44 & 29.1 & 4.85 & 7.29 & 11.29 & 0.65 & 832.84 & 1027.2 \\
\hline 2 & 37.7 & 23.5 & 2.55 & 3.56 & 4.52 & 0.79 & 675.9 & 431.21 \\
\hline 3 & 14.5 & 12.3 & 1.61 & 8.72 & 7.18 & 1.22 & 117.67 & 51.93 \\
\hline 4 & 15.3 & 7.8 & 1.51 & 6.95 & 4.58 & 1.52 & 76.73 & 30.96 \\
\hline 5 & 39 & 23.1 & 1.44 & 6.67 & 2.7 & 2.47 & 588.44 & 256.37 \\
\hline 6 & 43.1 & 35 & 6.08 & 15.94 & 15.55 & 1.03 & 996.13 & 1377.93 \\
\hline 7 & 21.7 & 18.8 & 3.46 & 10.47 & 11.12 & 0.94 & 337.41 & 284.79 \\
\hline 8 & 138 & 93.1 & 8.26 & 4.4 & 17.29 & 0.25 & 5993.84 & 9811.59 \\
\hline 9 & 26.9 & 26.8 & 2.53 & 7.43 & 9.54 & 0.78 & 416.03 & 249.71 \\
\hline 10 & 109 & 73.8 & 4.50 & 2.08 & 12.67 & 0.16 & 2741.56 & 2282.12 \\
\hline
\end{tabular}

The morphological characteristics calculated from the airborne LiDAR scan (Table 2) are comparable to those calculated from the terrestrial LiDAR scan (Table 3). In particular, the values calculated for volume demonstrate a statistically significant ranked order correlation between the results (Spearman rho $=1.000, \mathrm{n}=6, p<0.01$ ). Discrepancies between the surface area calculations are likely the result of differences in the perimeters derived from the two data sets used to isolate the mounds.

While based on only a small sample size from a restricted environmental context, these results support the feasibility of the use of airborne LiDAR in determining mound dimensions and extent. However, as the edited perimeters in Figure 5 suggest, some verification is required to check the validity of the mounds and perimeters identified, in addition to the considerations discussed above. While conceptually straightforward, determining where a mound stops, and therefore the boundary extent, may at times be difficult. Satellite or aerial imagery may provide a way to determine mound dimensions remotely, but in many cases, ground checking will still be required. Further development of the method is required to determine if shallow mounds such as those identified elsewhere in Cape York Peninsula may be detected (e.g. Larsen et al. 2017). The use of aerial data does, however, provide a more expedient way to calculate the metrics for mounds compared to terrestrial laser scanning. These data provide the opportunity to remotely survey areas within or adjacent to planned mining operations and might be used in the future to understand the frequency and extent of mounding activities across the wider Rio Tinto Weipa mining leases (ML7024 and ML7031).

Application of this approach to the Western area (Figure 11) indicates how the use of airborne LiDAR data might permit mound identification and characterisation. This area is at the western-most extent of the study location, and time constraints did not permit the mounds in this area to be assessed in detail during the field survey. Initial assessment of the airborne LiDAR data for this area identified several potential mounds, some of them of considerable size. However, high variability in ground surface topography compared to the Central area made use of a slope value of $5^{\circ}$ ineffective. Increasing the slope value to $10^{\circ}$ allowed identification of 10 mounds (Figure 11). Table 4 provides the derived dimensions, slope values, surface areas, and volumes for these mounds.

The mounds from the Western area represent a range of sizes, with Mound 8 the largest. This mound has multiple peaks and likely results from several smaller mounds merging and becoming inseparable with the current data. Volume estimates calculated using the techniques described above indicate its relative size. Dimensions for Mound 1 also indicate that it is a large mound, however, it sits on a natural ridge therefore the derived dimensions may vary depending on calculation of the base of the mound, following discussion above.

These issues highlight that while LiDAR data provide the potential for mound identification determining accurate dimensions often will require field survey, particularly when multiple mounds are in close proximity or there are variations in the natural topography on which mounds rest. The use of a $10^{\circ}$ slope value in the Western area also demonstrates the need to consider local conditions when determining a criterion for remote mound identification. To make effective use of LiDAR data, work is required to understand relationships between shell mound extent and regional topographies.

\section{Discussion}

Survey results demonstrate that riverside areas of Kwokkunum, like similar areas in Albatross Bay, contain many anthropogenic shell mounds that substantially vary in size and shape. At Kwokkunum, the shell mounds along with other features such as earth mounds and scarred trees, and portable artefacts like grinding dishes, constitute a cultural heritage landscape that invites questions about the kinds of behaviours that led to its creation. The distance between Kwokkunum and the current extent of mining operations, means that cultural heritage features removed or altered on the Weipa Peninsula over the last 60 years may remain intact at Kwokkunum. Consequently, Kwokkunum provides an opportunity to explore the spatial extent and temporality of landscape use by past Aboriginal peoples who moved across different landscape units, something that would be difficult to achieve from the record that remains across the modern-day Weipa Peninsula. 


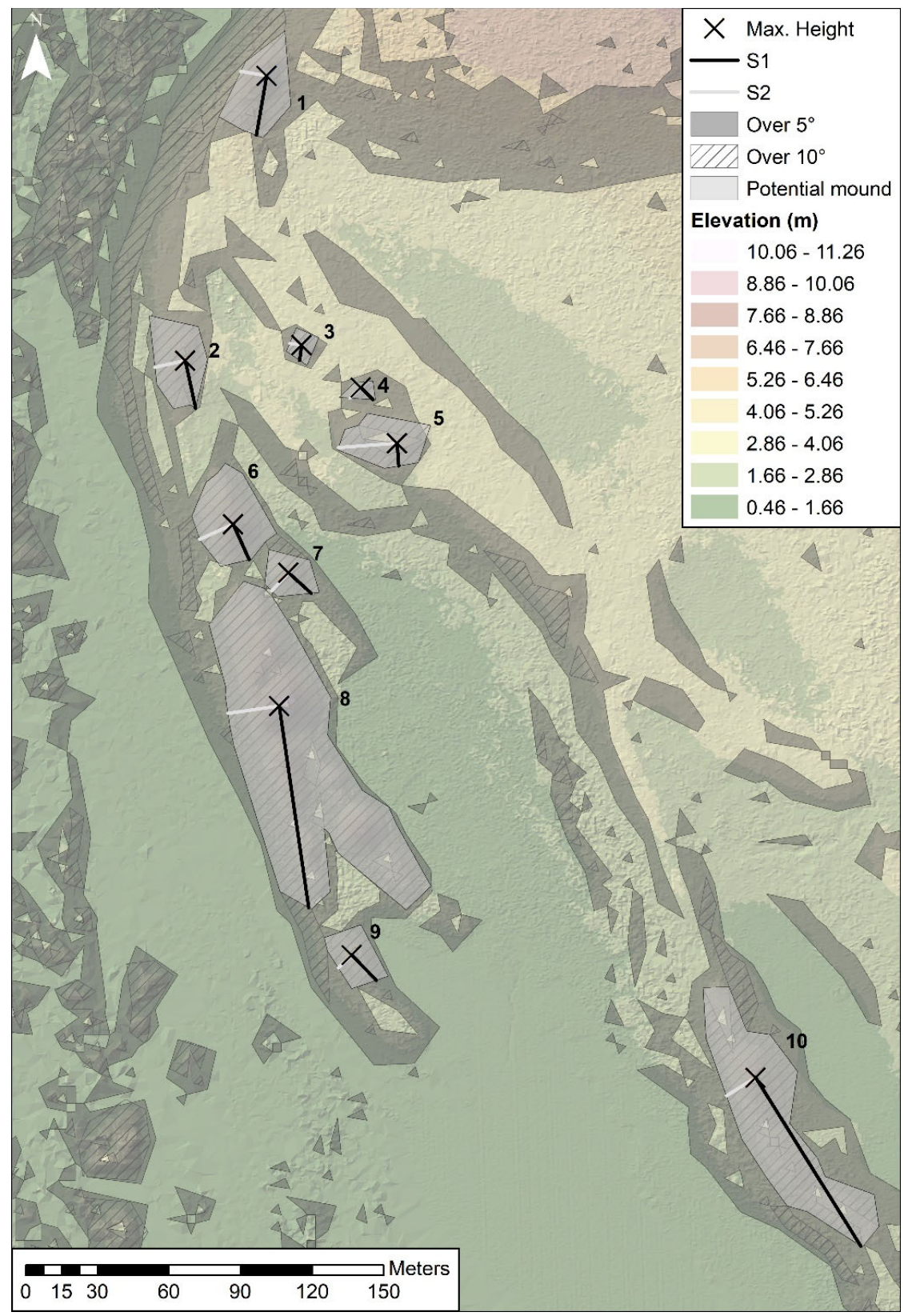

Figure 11. Mounds identified with airborne LiDAR data from the Western area.

As most of the shell mounds at Kwokkunum lie within environmental buffers or outside of the mining lease areas, mining activities are unlikely to have a direct impact on the sites recorded. Other contemporary activities thought to occur in the area such as recreational hunting are also unlikely to have a significant impact, with the exception of the hut construction referenced above. Aside from human activities, two probable sources of damage to shell mounds include trampling from feral ungulates, and excavation through periodic tree fall. Evidence of cattle and pigs, including scat and hoof-prints, were present on many shell mounds, with these species also seen during fieldwork. Animal trampling may crush near-surface shells leading to the relocation of loose shells and artefacts. In addition, many mounds feature large trees growing in the shell matrix, and these often dislodge following death or damage (Allely et al. submitted). These impacts are low at the individual level, but over long periods, multiple occurrences will change the shape of mounds and potentially affect their significance. Changes in the frequency and intensity of droughts and floods in the region will likely exacerbate this situation.

In order to understand the current form of the mounds, and how post-depositional processes continue to affect them, several lines of inquiry must be combined. The first is to identify the location, size, and shape of all the mounds in the Kwokkunum region using methods like those reported here. The location of mounds in relation to their different environmental contexts would help to reconstruct the past landscape conditions and use. The size of the mounds is quantifiable through terrestrial LiDAR scanning, however, the vegetation on some of the mounds presents an issue. The currently available airborne LiDAR data for the area creates results that are coarser than those from terrestrial scanning, but does allow filtering of ground vegetation and is therefore 
useful in identifying the potential locations, sizes, and numbers of mounds. Ground elevations of the mounds derived from airborne LiDAR may be used to create a filter for the elevations obtained from the terrestrial scans, effectively removing the vegetation from the data. Results presented here indicate the need to consider local topographic variability together with reconstructions of the shape of the mound bases.

The size of some of the mounds in the Kwokkunum region are of interest. Two of the mounds surveyed, SE-SM235 and SE-SM236 have volumes over $1000 \mathrm{~m}^{3}$ however analysis of airborne LiDAR data from areas further to the west indicates mound sizes considerably larger than those surveyed in-field (Table 4). Volumes estimated for shell mounds in the Albatross Bay region vary widely but confirm that some of the Kwokkunum mounds are among the largest found in the region. Figure 12 shows mound volume estimates collated by Morrison (2010:Appendix 2) plotted against estimates of mound height. Triangle and square icons in the figure indicate the Kwokkunum mounds, from the Central and Western areas respectively using airborne LiDAR data. Mounds greater than $8 \mathrm{~m}$ in height with volumes estimated to be in excess of $5000 \mathrm{~m}^{3}$ are comparatively rare in the Albatross Bay region. However, worldwide shell mounds attain very large volumes. Jabuticabeira II, in Santa Catarina, Brazil, for example is estimated to have a volume of $320,000 \mathrm{~m}^{3}$ while the Garopaba mound, Sambaqui, Brazil is around $700,000 \mathrm{~m}^{3}$ (Fish et al. 2000:70 cited in Fish et al. 2013). The Ehoussou shell midden, Ivory Coast is $270,000 \mathrm{~m}^{3}$ (Kouassi 2013). Ellis Landing Mound, California, is estimated at $35,649 \mathrm{~m}^{3}$ (Gifford 1916) and was similar in size to the Emeryville Shellmound, California at $39,000 \mathrm{~m}^{3}$ (Gifford 1916). In contrast, Deurspring 16, Malkoppan, Grootrif D and Grootrif G, Railway Midden, Mike Taylor's Midden, and Cape Deseada Midden in South Africa have estimated volumes of a few hundred to over $1000 \mathrm{~m}^{3}$ (Jerardino 2010, 2013). All these volume calculations are estimates since they were not measured using more precise techniques such as LiDAR. Additionally, as the results presented in this study indicate, even when such technologies are available, determining volume is not straightforward since it is dependent on surface condition and the ability to estimate the shape of the base of the mound. As well, studies of the Wathayn shell mounds indicate that post-depositional changes affect mound volume through shell fragmentation, sediment deposition, and compression. Therefore, mound volumes measured today may not reflect accurately mound volumes as they once were at particular times in the past (Allely et al. submitted).

To date, only the Wathayn study has produced the combinations of data sets needed from mounds in Albatross Bay to understand the history of mound deposition and subsequent transformation. In this study, terrestrial LiDAR scans of mounds were used to understand shape and symmetry of mounds (Larsen et al. 2017). Results were related to radiocarbon determinations from mounds (Holdaway et al. 2017) together with the results of geochemical analyses (Fanning et al. 2018), and shell mound sediment and shell fragmentation analyses (Allely et al. submitted). It is important that further areas are studied using similar multiproxy approaches to understand how mounds reached their current form. In such investigations, questions concerning mound age, how many people may have contributed to their construction, and the range of time over which they formed may be answered. However, at Kwokkunum the size of some of the mounds provide challenges for research. Previous research at Wathayn (Shiner et al. 2013; Holdaway et al. 2017) used a methodology that involved trenches excavated into the mounds to gain an understanding of stratigraphic layers and to provide samples of the shell matrix for sediment and geochemical analyses, and dating. Such an approach, while effective, may not be feasible for some of the mounds in the Kwokkunum area due to their size, and such excavation would pose both a logistical and health and safety challenge. Even at Wathayn, single trenches excavated into the centre of the mounds studied provided comparatively small samples, the proportion dependent on the size of the mound since all trenches were no more than $1 \mathrm{~m}$ wide. We do not know the impact of internal variation within individual mounds on, for example, chronology. Equally significantly, we are not able to tell from the shape or size of mounds, nor their relative locations, which are the oldest or indeed which may be contemporary in age (Holdaway et al. 2017). Based on the Wathayn results, mounds that are closely spaced may have quite different postdepositional histories (Allely et al. submitted). Thus, assessment of significance must rely on descriptive criteria. For example, current significance assessments are based on estimates of integrity (degree of disturbance), contents (range and type of occupation debris), and representativeness or rarity. While part of a recognised process for survey significance assessment, any one of these criteria requires detailed analysis before values can be determined. At Wathayn, results are available that might allow such significance assessment but only after years of analysis. Currently such data are lacking for the Kwokkunum area.

Despite the decades of previous research on the Albatross Bay shell mounds, more research is needed. There remain key issues that we currently lack techniques to overcome. The size of some of the Kwokkunum mounds make these particularly challenging. Excavating trenches into the larger mounds pose technical challenges, and there are challenges in understanding variation in the internal structure of the mounds. An ideal approach to understanding such variation would aim to minimise extensive excavation. Two methods that might be used to achieve this are ground penetrating radar (GPR) and electrical resistivity tomography (ERT). GPR is a non-invasive method that uses radar pulses to measure the differential electrical resistances of subsurface layers (Goodman and Piro 2013). This involves the movement of a radio antenna across the surface of the ground, either by carrying a machine or placing it on a cart. While the method has not been extensively used to date to investigate shell mounds, there has been some work on the feasibility of the method. Preliminary studies that use GPR on shell mounds have found it to be able to characterize different depositional instances within shell matrices (Rosendahl et al. 2014). This method would be useful in order to characterise the depositional sequences of some of the shell mounds in the Kwokkunum area. In addition, such data may provide a way to measure the shape of the base of the shell mounds that would enable the creation of more robust volume calculations.

While GPR provides a way to understand subsurface deposits and their relationship to each other, the technique may not be logistically feasible on some mounds due to the slope of their edges or the vegetation covering them. Instead, ERT provides a way to overcome these obstacles. ERT is a 


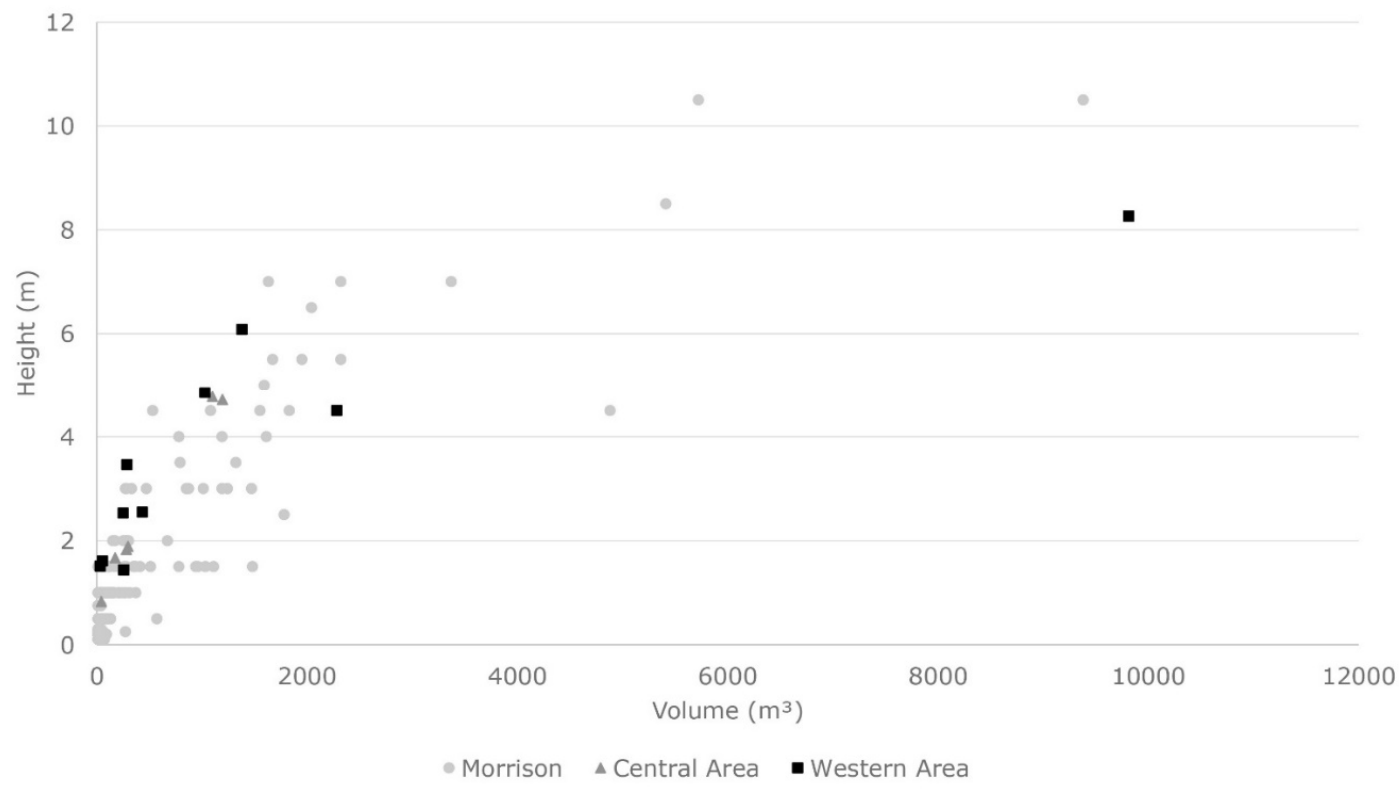

Figure 12. Estimated shell mound volume versus estimated shell mound height plotted from data compiled by Morrison (2010:Appendix 2), with volume and height calculations from the Central area (Table 3), and estimates from the Western area (Table 4) of Kwokkunum.

minimally-invasive technique that involves the placement of a series of probes across a section, the position and extent of which determines the depth that is measured. An electrical current runs through the probes recording the differential electrical resistivity of the subsurface deposits (Mol and Preston 2010). Multiple sections generated from GPR and ERT combined would allow for the creation of a threedimensional model of the subsurface deposits, potentially showing different shell depositional events.

These methods do not help answer questions regarding the age of the mounds and only indirectly indicate what postdepositional processes may have affected them. To answer these questions analysis of the shell matrix and the sampling of material for radiocarbon age determinations is required. The results of GPR and ERT could, however, provide information about areas to sample in order to obtain a representative sample of the identified layers. Extraction of the shells and the matrix might be achievable through coring (Stein 1986), although a coring method that ensures minimal damage to the shell matrix would need to be developed.

Determining why mounds occur in such different sizes remains a challenge. We know that numbers of mounds formed at the same time, but we lack a good understanding of why this occurred or the longevity of all mounds (Holdaway et al. 2017). There is evidence that mound shape has changed through shell fragmentation, but we lack detailed understanding how this varied in the different environmental zones that exist in areas like Kwokkunum. The shell mounds at Kwokkunum stand out because some of them are truly substantial structures, some of the largest Aboriginal structures in Australia. Traditional Owners are eloquent in their assessment of Aboriginal cultural significance of the mounds. The challenge for archaeologists working with their industry partners is to develop the methods to provide Traditional Owners with information they desire about the age and formation history of the mounds.

\section{Conclusion}

A short period of fieldwork allowed initial assessment of the presence, size, and shape of some of the shell mounds in the Kwokkunum region. The region is significant because unlike the Weipa Peninsula it has not to date been subjected to extensive bauxite mining. Shell mounds vary in size with some examples amongst the largest found in Albatross Bay. Comparison of terrestrial and airborne LiDAR data suggests that shell mounds may be identified remotely where mound slopes exceed $5-10^{\circ}$ although in-field checking is required to identify low-lying mounds and shell scatters. The current LiDAR data do not allow the identification of CMT or portable artefacts. Vegetation provides significant challenges for the recording of shell mounds and vegetation on the mounds themselves is likely having an impact on their form and preservation.

The largest shell mounds provide significant challenges for future research. Dating mounds requires excavation to obtain samples and samples from within the mounds are also needed to assess changes in mound composition. GPR and ERT may provide opportunities to remotely determine the subsurface structure of mounds and, if technical issues connected with coring can be solved, it may be possible to obtain samples without extensive excavation. Despite the limited duration of fieldwork at Kwokkunum, survey results suggest that the region has the potential to provide significant information concerning Aboriginal use of the region enhancing heritage significance assessment.

\section{Acknowledgements}

The authors would like to thank the Anathangayth and Thanakwith Traditional Owners of the area. Anathangayth Traditional Owners Anna Motton, Faye Motton, Jesse Motton, Yosinta Motton, Florence Motton, Morris Woodley and Johnny Woodley assisted during the field survey. Thanks also to Anna Kreij for assistance during the survey. Funding for the survey was provided by Rio Tinto. 


\section{References}

Allely, K., S.J. Holdaway, P.C. Fanning and G.N. Bailey submitted Shell mound deposit composition and preservation. Quaternary International.

Bailey, G.N. 1975 The Role of Shell Middens in Prehistoric Economies. Unpublished $\mathrm{PhD}$ thesis, University of Cambridge, Cambridge.

Bailey, G.N. 1977 Shell mounds, shell middens, and raised beaches in the Cape York Peninsula. Mankind 11(2):132-143. https://doi.org/ 10.1111/j.1835-9310.1977.tb01175.x

Bailey, G.N. 1994 The Weipa shell mounds: Natural or cultural. In M. Sullivan, S. Brockwell and A. Webb (eds), Archaeology in the North: Proceedings of the 1993 Australian Archaeological Association Conference, pp.107-129. Darwin: North Australia Research Unit, Australian National University.

Bailey, G.N., J. Chappell and R. Cribb 1994 The origin of Anadara shell mounds at Weipa, North Queensland, Australia. Archaeology in Oceania 29(2):69-80. https://doi.org/10.1002/arco.1994.29.2.69

Bourke, P.M. 2004 Three Aboriginal shell mounds at Hope Inlet: Evidence for coastal, not maritime late Holocene economies on the Beagle Gulf mainland, northern Australia. Australian Archaeology 59:10-22. https://doi.org/10.1080/03122417.2004.11681787

Cochrane, G. 2014 Marcia hiantina shell matrix sites at Norman Creek, western Cape York Peninsula. Australian Archaeology 78(1):47-52. https://doi.org/10.1080/03122417.2014.11681998

Cribb, R. 1986 A preliminary report on archaeological findings in Aurukun Shire, western Cape York. Queensland Archaeological Research 3:133-158. https://doi.org/10.25120/qar.3.1986.185

Cribb, R. 1996 Shell mounds, domiculture and ecosystem manipulation on western Cape York Peninsula. In P. Veth and P. Hiscock (eds), Archaeology of Northern Australia: Regional Perspectives, pp.150-174. Tempus 4. St Lucia, QLD: Anthropology Museum, University of Queensland.

Davis, D.S., M.C. Sanger and C.P. Lipo 2019 Automated mound detection using lidar and object-based image analysis in Beaufort County, South Carolina. Southeastern Archaeology 38(1):23-37. https://doi.org/10.1080/0734578X.2018.1482186

Fanning, P.C, S.J. Holdaway and K. Allely 2018 Geoarchaeology in action: A sedimentological analysis of anthropogenic shell mounds from the Cape York region of Australia. Quaternary International 463(A):44-56. https://doi.org/10.1016/j.quaint.2016.09.010

Faulkner, P. 2009 Focused, intense and long-term: Evidence for granular ark (Anadara granosa) exploitation from late Holocene shell mounds of Blue Mud Bay, northern Australia. Journal of Archaeological Science 36(3):821-834. https://doi.org/10.1016/ j.jas.2008.11.005

Fish, P.R., S.K. Fish, P. Deblaasis and M.D. Gaspar 2013 Monumental shell mounds as persistent places in southern coastal Brazil. In V.D. Thompson and J.C. Waggoner Jr. (eds), The Archaeology and Historical Ecology of Small Scale Economies, pp.120-140. Miami: University Press of Florida. https://doi.org/ $\underline{10.5744 / \text { florida/9780813042428.003.0007 }}$

Gifford, E.W. 1916 Composition of California shellmounds. University of California Publications in American Archaeology and Ethnology 12(1):1-29.

Goodman, D. and S. Piro 2013 GPR Remote Sensing in Archaeology. Berlin: Springer. https://doi.org/10.1007/978-3-642-31857-3

Harrison, R. 2009 The archaeology of the Port Hedland coastal plain and implications for understanding the prehistory of shell mounds and middens in northwestern Australia. Archaeology in Oceania 44(S1):81-98. https://doi.org/10.1002/j.1834-4453.2009.tb00070.x
Hiscock, P. 2007 Archaeology of Ancient Australia. London: Routledge. https://doi.org/10.4324/9780203448359

Holdaway, S.J, P.C. Fanning, F. Petchey, K. Allely, J.I. Shiner and G.N. Bailey 2017 Temporal variability in shell mound formation at Albatross Bay, northern Australia. PloS ONE 12(8):e0183863. https://doi.org/10.1371/journal.pone. 0183863

Jerardino, A. 2010 Large shell middens in Lamberts Bay, South Africa: A case of hunter-gatherer resource intensification. Journal of Archaeological Science 37(9):2291-2302. https://doi.org/10.1016/ j.jas.2010.04.002

Jerardino, A. 2013 Mega shell middens and hunter-gatherer resource intensification along the west coast of South Africa. In G.N. Bailey, K. Hardy and A. Camara (eds), Shell Energy: Mollusc Shells as Coastal Resources, pp.207-228. Oxford: Oxbow Books.

Kreij, A. 2016 Archaeological Survey of Access Track and Proposed Drilling Locations in Kwokkunum (Embley) on ML7024. Unpublished report to Rio Tinto, Weipa.

Kouassi, S.K. 2013 Ceramic decorations from the Songon Kassemblé shell midden, Côte d'Ivoire: A contribution to the understanding of decorative symbols in Africa. In G.N. Bailey, K. Hardy and A. Camara (eds), Shell Energy: Mollusc Shells as Coastal Resources, pp.199-206. Oxford: Oxbow Books.

Larsen, B.P., S.J. Holdaway, P.C. Fanning, T. Mackrell and J.I. Shiner 2017 Shape as an outcome of formation history: Terrestrial laser scanning of shell mounds from far north Queensland, Australia. Quaternary International 427(A):5-12. https://doi.org/10.1016/ i.quaint.2015.06.066

Mol, L. and P.R. Preston 2010 The writing's in the wall: A review of new preliminary applications of electrical resistivity tomography within archaeology. Archaeometry 52(6):1079-1095. https://doi.org/ 10.1111/j.1475-4754.2010.00516.x

Morrison, M. 2002 Cultural Heritage Desktop Study: Removal of Illegal Fishing Huts at the Hey River, Weipa. Unpublished report to Rio Tinto, Weipa.

Morrison, M. 2010 The Shell Mounds of Albatross Bay: An Archaeological Investigation of Late Holocene Production Strategies near Weipa, North Eastern Australia. Unpublished $\mathrm{PhD}$ thesis, Department of Archaeology, Flinders University, Adelaide.

Morrison, M. 2013 Niche production strategies and shell matrix site variability at Albatross Bay, Cape York Peninsula. Archaeology in Oceania 48(2):78-91. https://doi.org/10.1002/arco.5002

Rio Tinto Alcan Pty Ltd 2011 Environmental Impact Statement for South of Embley Project. Weipa: Rio Tinto Alcan Weipa Pty Ltd.

Rosendahl, D., K.M. Lowe, L.A. Wallis and S. Ulm 2014 Integrating geoarchaeology and magnetic susceptibility at three shell mounds: A pilot study from Mornington Island, Gulf of Carpentaria, Australia. Journal of Archaeological Science 49:21-32. https://doi.org/ 10.1016/j.jas.2014.04.017

Shiner, J. and M. Morrison 2009 The contribution of heritage surveys towards understanding the cultural landscape of the Weipa bauxite plateau. Australian Archaeology 68:52-55. https://doi.org/10.1080/ $\underline{03122417.2009 .11681890}$

Shiner, J.I., P.C. Fanning, S.J. Holdaway, F. Petchey, C. Beresford, E. Hoffman and B.P. Larsen 2013 Shell mounds as the basis for understanding human-environment interactions in Far North Queensland, Australia. Queensland Archaeological Research 16:65-92. https://doi.org/10.25120/qar.16.2013.224

Smart, J. 1977 Weipa Queensland, Sheet SD/54-3 1:250 000 Geological Series Explanatory Notes. Canberra: Bureau of Mineral Resources. 
Stanner, W.E.H. 1961 The Weipa shell-mounds. The Etruscan 11(2):8-12.

Stein, J.K. 1986 Coring archaeological sites. American Antiquity 51(3):505-527. https://doi.org/10.2307/281749

Stone, T. 1992 Origins of the Weipa Shell Mounds. Unpublished MSc thesis, Australian National University, Canberra.
Citation: Emmitt, J., K. Allely, B. Davies, E. Hoffman and S.J. Holdaway 2020 Preliminary archaeological survey and remotesensing of shell mounds at Kwokkunum, Albatross Bay, Cape York Peninsula, Australia. Queensland Archaeological Research 23:9-24. https://doi.org/10.25120/qar.23.2020.3718 